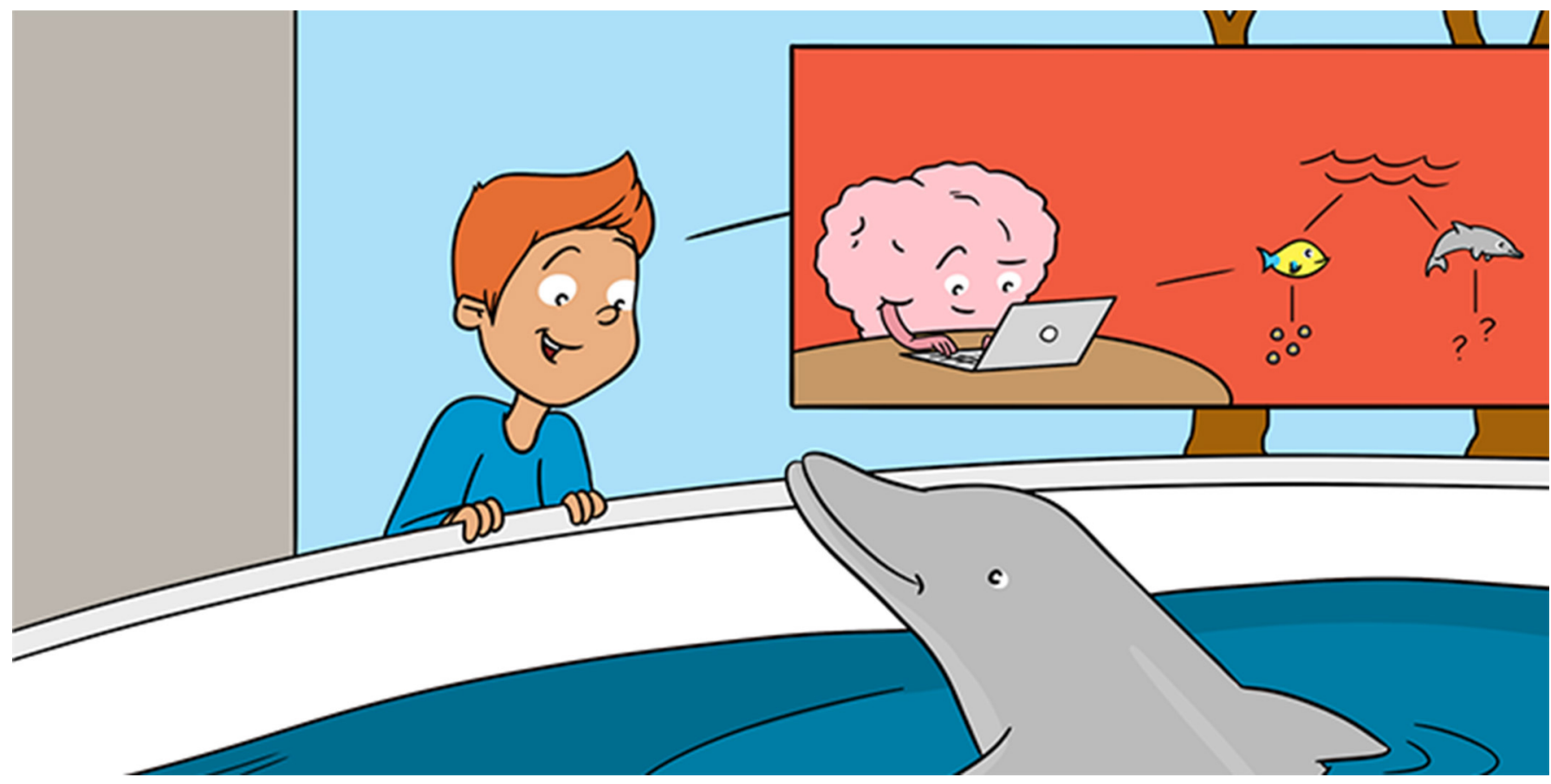

\title{
HOW TO USE YOUR MEMORIES TO HELP YOURSELF LEARN NEW THINGS
}

\section{Marlieke van Kesteren * and Martijn Meeter}

Department of Education Sciences, Vrije Universiteit Amsterdam, Amsterdam, Netherlands

\section{YOUNG REVIEWERS:}

DR.

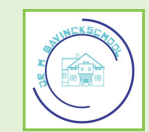

H. BAVINCK SCHOOL

AGES: 8-12

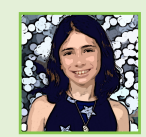

ELIZA

AGE: 10

MALLETS

BAY SCHOOL

AGES: 9-10
Remembering is an essential brain function. Think about it-what would happen if you did not remember anything? You would not be able to recall the things you learn at school. Actually, you would not even know that you had to go to school, or where your school is! Many people think that memory can be compared to a closet, where you put something and later retrieve it the same way you put it in. But this is not really how it works. In fact, memory works more like news websites on the internet that keep changing content depending on what happens in the world. A good website also includes links to other websites where you can look up related information. Whether you remember something well depends on many things that happen in your brain during and after learning. One factor that is very important for learning is the knowledge that is already stored in your brain. When you already know a lot, it is easier to add new information. We will also show you how you can use this knowledge about how memories are formed to help you remember new things you learn at school. 


\section{SCHEMA}

Prior knowledge in your brain.

\section{HIPPOCAMPUS}

A brain region that helps you to remember by linking different parts of a memory together.

\section{Figure 1}

This is a picture of your brain cut through the middle. You can see both the hippocampus, in red, and the medial prefrontal cortex, in blue. The hippocampus links separate parts of a memory, making sure the memories stay detailed and vivid, such as when you remember that time when your goldfish laid eggs. The medial prefrontal cortex can also help you to remember information, but it is thought to do so by integrating new knowledge with existing schema knowledge, so the memories become less detailed and more generalized. This process can also lead to misconceptions, such as when you mistakenly think that a dolphin, because it resembles a fish, also lays eggs while in fact it gives birth to live baby dolphins. Adapted from: https://commons. wikimedia.org/wiki/File: Frog-spawn-Ranatemporaria-11d.svg and http://www.clker.com/ clipart-brain-3.html.

\section{YOUR PREVIOUS KNOWLEDGE MAKES IT EASIER TO LEARN}

Take a moment to think about everything you already know. Consider life events, the people you know, books you have read, games you have played, stuff you have learned at school, et cetera... It is a lot, right? Well, it is very useful to have all this knowledge stored in your brain. This knowledge helps you to understand the world around you, but it also makes learning new information easier, since you can link the new information with what you already know. For example, when you already know some things about the brain because you have read Frontiers Young Minds Neuroscience articles before, it will probably be easier for you to remember what we are about to tell you. The neuroscience knowledge in your brain makes it more likely for new memories to "stick." We call such a knowledge structure a schema [1].

\section{HOW MEMORY WORKS IN YOUR BRAIN}

In the brain, there are many regions that help to store memories. The most important one is called the hippocampus (which means seahorse, because it is shaped like a seahorse). Without your hippocampus you could not learn new information [2]. Scientists think that the hippocampus links different parts of a memory together. For example, when you learn that fish lay eggs, the hippocampus makes a connection between "fish" and "eggs" (see Figure 1). This means that the memory itself is not in the hippocampus, but without the help of the hippocampus, you could not link the different parts of the memory together. This happens when forget something: the different parts of the memory are still there, but they cannot be connected anymore.

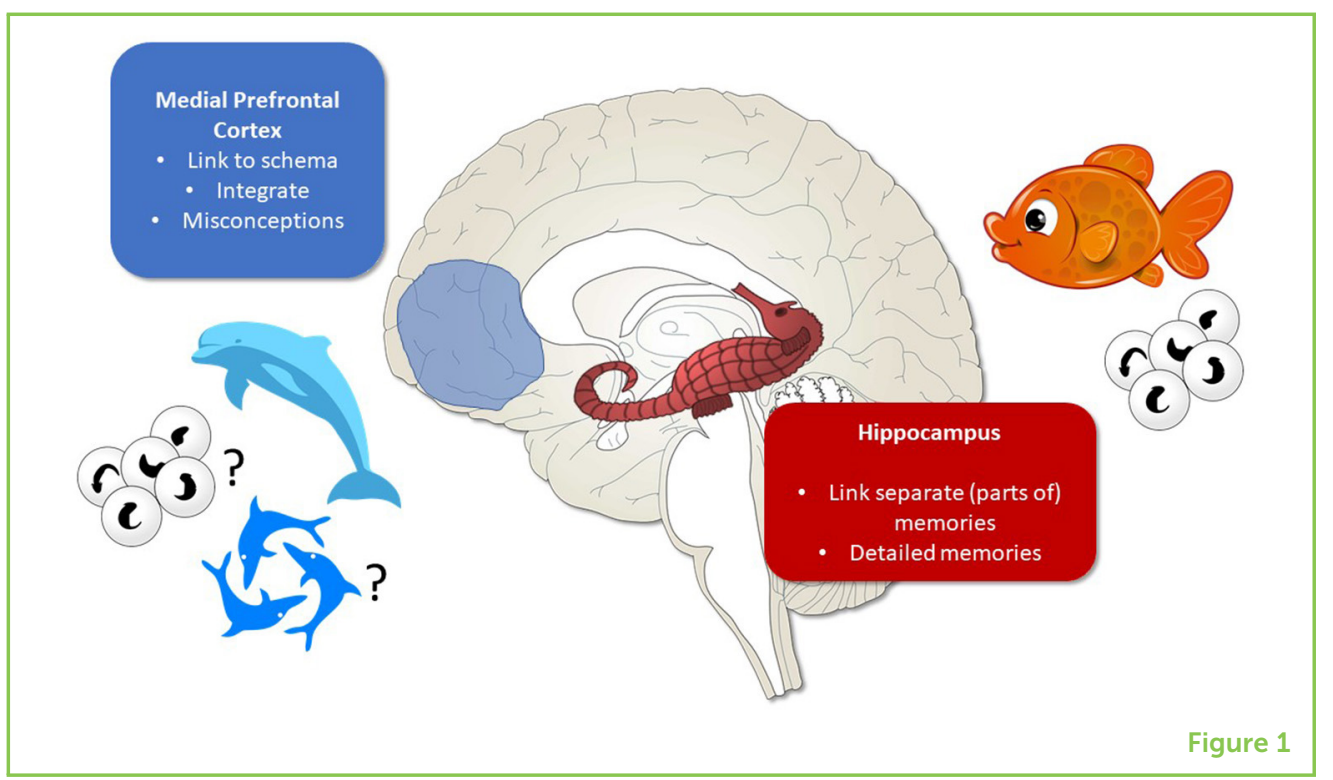


MEDIAL

PREFRONTAL

\section{CORTEX}

A brain region that helps you to integrate new memories with your schema knowledge.

\section{METHOD OF LOCI}

A memory technique in which you link things that you want to remember to a well-known place.
Another brain region, called the medial prefrontal cortex, can also help you remember information, but scientists think that this region learns differently than the hippocampus [3]. Based on your schema knowledge, the medial prefrontal cortex figures out where to best place new information and then connects it with your schema. This means that when you learn a new type of fish, like a goldfish, your medial prefrontal cortex will immediately connect that to "laying eggs," because that is what you have remembered before. This process is called integration, which means to combine into one. The integration process helps you to uncover connections between new and old knowledge For example, if you know that fish lay eggs and that a goldfish is a fish, you could uncover that goldfish lay eggs [4]. This is a new fact that your medial prefrontal cortex helped you discover. So, you can see that it can be helpful to use this integration process when learning new information.

\section{SCHEMAS AT SCHOOL}

Especially at school, it can be very helpful to actively use your schema knowledge when you learn new information [5]. You can do this in different ways. Before starting a lesson, you can revisit what you have learned before about a certain topic (for example, that fish lay eggs). Or, while studying, you can pause often and think about what you just learned and how the new knowledge links to what you already know. This will help you to use your medial prefrontal cortex to integrate new information and remember it better for tests. In addition, such integration helps you to build better schemas so you can remember new, related information even better in the future.

Sometimes, we can use memory "tricks" to link new knowledge to our schema knowledge. For example, when learning a list of words, you can link these words to places in your room or another familiar environment. This is called the method of loci (loci means "places" in Latin [6]). It is used by many people to remember arbitrary information that is hard to connect to schema knowledge, like a long grocery list. While you look at the grocery list, you can imagine every item somewhere in your living room (for example, a box of ice cream on the couch), and when you are in the supermarket, you just have to think about your couch to remember what you wanted to buy. With a bit of training, this method will work for you too!

\section{BE AWARE OF INCORRECT MEMORIES}

Unfortunately, it is not all good news. Relying very strongly on schema knowledge can also lead to incorrect memories. For example, consider the "fish lay eggs" example we gave earlier. What happens when you then learn about dolphins? Because dolphins look like other fish, and you already know a lot about fish, you could think that they 
MISCONCEPTION

A wrong memory. lay eggs as well. However, this is not true. Dolphins are mammals, so dolphins give birth to live dolphin babies, just like humans. We call such false memories misconceptions. These misconceptions can arise when your schema knowledge about something (in this case how fish make babies) is very strong. The misconception will make it very hard to remember when you learn something that does not fit (that the dolphin does not lay eggs). In this case, your medial prefrontal cortex should not integrate the dolphin with your fish schema. Instead, your hippocampus should kick in to make a separate memory. How do you do this?

\section{TIPS}

Here are a few tips to help you use your schema knowledge when learning new things at school. These tips should also help you to avoid or get rid of misconceptions:

Reactivate: When you learn new information, reactivate related schema knowledge. Close your eyes and take a moment to remember what you have learned about this topic before and how it connects to the new information you want to learn.

Elaborate: Try to link new information to different kinds of schema knowledge. For example, when you must learn in biology that dolphins are mammals, you can now link it to your memories about schemas and the example of fish that you read here. The more links you make, the better you can integrate new information and remember it well. Making strong and detailed links can also avoid the formation of misconceptions.

Space, repeat, and alternate: You can best create and extend schemas by learning and repeating new information in small pieces over time: hours, days, even weeks. Alternating different topics, so you do not always study the same thing, can also benefit your memory.

Recall and ask questions: After you have learned something, put away your book or computer and try to remember what you have just learned, just by using your brain. Or, you can ask questions about what you learned. This will help you to integrate information and you can use the questions later to quiz yourself and your classmates. To avoid misconceptions, make sure you always check whether your memory was correct!

Teach others: A very good way to organize your schemas is to teach your classmates. Take turns: read something, link it to your schema knowledge, let it sink in, then try to explain it to someone else. Again, always check afterwards whether you have made mistakes and discuss things you do not really understand.

Sleep: Perhaps this is the odd one out because it does not happen at school, but sleep helps build strong schemas, and helps you 
forget less important information. Think about that when your parents tell you it is time for bed!

Track misconceptions: Always be aware when information contradicts your schema knowledge or when you notice that you have formed a misconception along the way. Try to make a new, very vivid memory. For the dolphin example, think about a funny dolphin with a very big belly who is jumping out of the water and squeaking loudly. Imagine how wet you will get and how you will pat its nose and feed it a fish. The more details and senses you use for this memory, the better!

\section{ENJOY!}

Try using these tips when you are learning new things at school or at home, and you will notice that you will remember a lot better. We hope this article will help you to enjoy learning!

\section{ACKNOWLEDGMENTS}

We would like to wholeheartedly thank those who assisted in the translation of the articles in this Collection to make them more accessible to kids outside English-speaking countries, and for the Jacobs Foundation for providing the funds necessary to translate the articles. For this article, we would especially like to thank MK for the Dutch translation. This project has received funding from the European Union'snion's Horizon 2020 research and innovation programme under the Marie Sklodowska-Curie grant agreement No 704506

\section{REFERENCES}

1. Bartlett, F. C. 1932. Remembering: A Study in Experimental and Social Psychology. Cambridge: University Press.

2. Squire, L. R. 1992. Memory and the hippocampus: a synthesis from findings with rats, monkeys, and humans. Psychol. Rev. 99:195-231.

3. van Kesteren, M. T. R., Ruiter, D. J., Fernandez, G., and Henson, R. N. 2012. How schema and novelty augment memory formation. Trends Neurosci. 35:211-9. doi: 10.1016/j.tins.2012.02.001

4. Schlichting, M. L., and Preston, A. R. 2015. Memory integration: neural mechanisms and implications for behavior. Curr. Opin. Behav. Sci. 1:1-8. doi: 10.1016/j.cobeha.2014.07.005

5. van Kesteren, M. T. R., Krabbendam, L., and Meeter, M. 2018. Integrating educational knowledge: reactivation of prior knowledge during educational learning enhances memory integration. NPJ Sci. Learn. 3:11. doi: 10.1038/s41539-018-0027-8

6. Available online at: https://en.wikipedia.org/wiki/Method_of_loci (accessed on 8 February 2020). 
SUBMITTED: 19 September 2019; ACCEPTED: 26 March 2020;

PUBLISHED ONLINE: 29 April 2020.

EDITED BY: Nienke Van Atteveldt, Vrije Universiteit Amsterdam, Netherlands

CITATION: van Kesteren M and Meeter M (2020) How to Use Your Memories to Help Yourself Learn New Things. Front. Young Minds 8:47. doi: 10.3389/frym.2020. 00047

CONFLICT OF INTEREST: The authors declare that the research was conducted in the absence of any commercial or financial relationships that could be construed as a potential conflict of interest.

COPYRIGHT () 2020 van Kesteren and Meeter. This is an open-access article distributed under the terms of the Creative Commons Attribution License (CC BY). The use, distribution or reproduction in other forums is permitted, provided the original author(s) and the copyright owner(s) are credited and that the original publication in this journal is cited, in accordance with accepted academic practice. No use, distribution or reproduction is permitted which does not comply with these terms.

\section{YOUNG REVIEWERS}

\section{DR. H. BAVINCK SCHOOL, AGES: 8-12}

We are Spectrum classes 5-6 and 7-8 of the Bavinckschool in Haarlem, the Netherlands. This is a group of 40 kids (19 in group 5-6 and 21 in group 7-8) who are eager to learn a bit more than the regular school program. They had a lot of fun reviewing for FYM, and went through the articles with great focus and enthusiasm, and made a critical evaluation. They really enjoyed contributing to science and helping out!

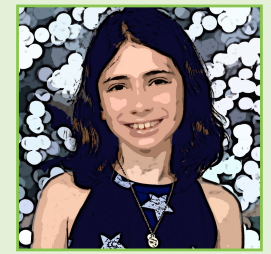

\section{ELIZA, AGE: 10}

Hi! My name is Eliza. I love to read and bake muffins. I have two dogs, named Arnie and Benji. I also like to do math with my dad. My mom has a Ph.D. in neuroscience, which I think is really interesting.

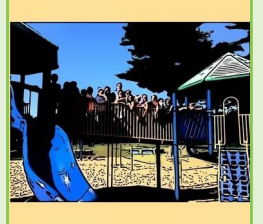

\section{MALLETS BAY SCHOOL, AGES: 9-10}

These fourth graders love the outdoors of their beautiful state, where winters are long, summers are short, and the mud season is always around the corner. They also enjoy playing American football, hotwheels, fortnite, and hockey.

\section{AUTHORS}

\section{MARLIEKE VAN KESTEREN}

Marlieke van Kesteren is a post-doctoral researcher in Educational Neuroscience at VU University Amsterdam. She investigates how we can best use our prior knowledge to learn new information. To do this she puts students in an MRI 


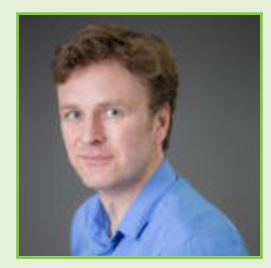

scanner while they are learning new things. She really likes to teach her findings to children in schools and is thrilled to be able to do this through Frontiers Young Minds. *marlieke.van.kesteren@vu.nl

\section{MARTIJN MEETER}

Martijn Meeter is a professor of education sciences, the science of how education works. His lab is at a university in Amsterdam, the Netherlands (www.vu.nl). He studies learning and education with many different techniques, and has built a lot of computer models of the brain: programs that simulate in a computer how our brain works. He is also the director of a teacher training program, a school that turns students into teachers for secondary education. 